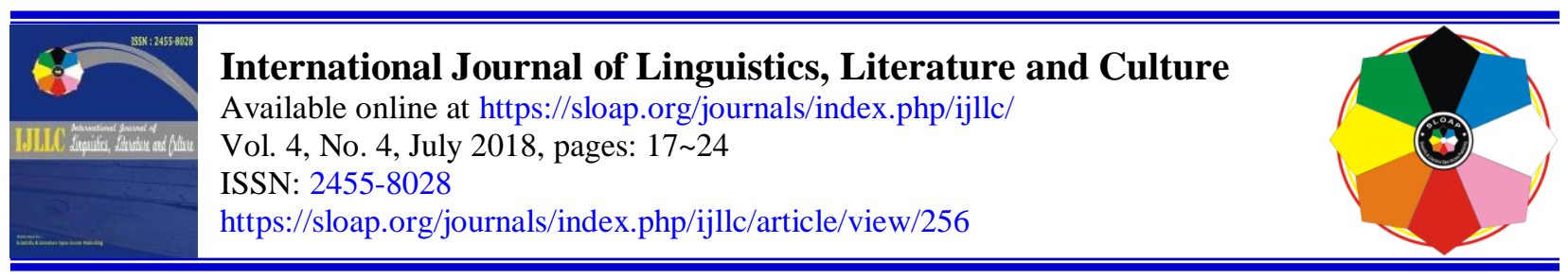

\title{
On the Postmodernity in A Dictionary of Maqiao
}

Jing Guo $^{\text {a }}$

Article history:

Received: 10 February 2018

Revised: 25 June 2018

Approved: 3 July 2018

Published: 7 July 2018

Keywords:

Feminism;

Narrative;

Discourse;

Postmodernity;

A Dictionary of Maqiao;
Abstract

A Dictionary of Maqiao, a novel written by Chinese writer Han Shaogong and translated into English by Julia Lovell, is first published in 1996 by The Writers Publishing House and selected by Yazhou Zhoukan as one of the top hundred greatest Chinese novels in the 20th century. Written in the form of a dictionary, or more accurately an encyclopedia, instead of a normal novel form, this novel depicts stories happened in Maqiao, a noteless village in Hunan Province, China. In the theoretic framework of postmodernism, this paper probes into Han Shaogong's A Dictionary of Maqiao, so as to analyze and illustrate in the representative stories the manifestations of postmodern theories, mainly theories of discourse, narrative, and feminism.

2455-8028 ${ }^{\circ}$ Copyright 2018. The Author. This is an open-access article under the CC BY-SA license (https://creativecommons.org/licenses/by-sa/4.0/) All rights reserved.

\section{Author correspondence:}

Jing Guo,

School of Foreign Languages, Shanxi Normal University,

Linfen, Shanxi, China.

Email address: guojing@sxnu.edu.cn

\section{Introduction}

Maqiao Cidian, a novel written by Chinese writer Han Shaogong was first published on the journal Fiction World (No. 2) by The Writers Publishing House in 1996 and selected as one of the top hundred greatest Chinese novels in the $20^{\text {th }}$ century by Asia Weekly in 1999. The English version A Dictionary of Maqiao, translated by Julia Lovell, British translator of modern Chinese literature, was published in 2003, and soon there were other language versions following subsequently, thus this novel aroused the attention of scholars across the globe. Written in the form of a dictionary, or more accurately an encyclopedia, instead of a normal novel form, this novel depicts stories happened in Maqiao, a noteless village in Hunan Province, China, from the perspective of a young man as an Educated Youth who was sent there due to the Down to the Countryside Movement in the Proletarian Cultural Revolution. First-person narration is employed in the stories, and the narrator "I" is a curious, moderate and intelligent young man. As an outsider to the village, he hardly blindly censures the unenlightenment and primitiveness of rural area as previous vernacular novels do, nor enthusiastically extol the simplicity and unadornment of the countryside. Instead, he integrates himself into the history of Maqiao and experiences its originality without any distance. Stories happened in Maqiao can roughly fall into three categories: political stories as Bandit Ma and Yanzao, Folklore stories about daily life in the countryside as

${ }^{\text {a }}$ School of Foreign Languages, Shanxi Normal University 
Zhihuang, and stories which can hardly be interpreted or narrated in ordinary discourse even in the context of the countryside, such as Tiexiang, Wanyu, Maming.

A Dictionary of Maqiao has won the praise of critics and the hearts of readers worldwide and has sparked a considerable number of comments and analyses from various perspectives. Extensive and profound criticism of the book has been made on the bantering nature of its unique genre, on translator's choices from Bourdieu's sociological perspective, on its interpretation in the theoretical framework of magic realism, on the manifestation of Chinese Rootseeking Literature, so on and so forth. Nevertheless, it is notable that the postmodern implication embodied in the book has not been touched upon, therefore, this paper is intended to approach this unheeded area from the perspectives of discourse, narrative, and feminism in the framework of postmodernism, and differentiate itself from former studies.

\section{Research Methods}

\section{Theoretical Framework and Analytical Methods}

With the emergence of D. C. Somervell's introduction to Arnold Joseph Toynbee's A Study of History, a twelvevolume analysis of the rise and fall of civilizations, the concept of postmodernism appears after the Second World War as a departure from the period of modernism. The postmodern period is a "Time of Troubles" (Best \& Kellner, 1991), featured by the collapse of rationalism and enlightenment. From the 1980s onwards, postmodernism flourished across the world, especially in France.

Attentions are to be paid not only to the negative denotation of "post", namely the end of certain outdated matters but also to its apocalyptic connotation, that is the birth of something new. On one hand, postmodernism depicts a phenomenon that is not modern, which can be interpreted as a positive negation and attempted transcendence of modern theory and culture. On the other, postmodernism demonstrates dependence on and continuity from the previous modern period, thus some critics regard it as "hypermodernity". What was once the romantic space of the literary becomes, for postmodernism, a general plane of human existence, on which concepts of identity, origin, and truth are seen as multiple and structureless assemblages rather than as grounds for an understanding of human being and culture. Niall Lucy holds, in her Postmodern Literary Theory, "postmodernism refers to the generalization or flattening out of the romantic theory of literature which marks it as a radical theory of the non-foundational, structureless structure of truth" (1997).

Chesterman's causal methodological model as the overall methodological model employed, this thesis makes a comprehensive exploration of postmodernity in A Dictionary of Maqiao. Based upon close reading and descriptive approach, this thesis attempts to prove this work does cohere to certain postmodern theories by providing representative stories and evidence in the text respectively of the postmodern theory of discourse, narrative, and feminism.

\section{Results and Analysis}

\subsection{Postmodernity from the Discoursive Perspective}

In The Archaeology of Knowledge of Michel Foucault, whose critique of modernism and humanism, announcement of the Death of Man, and innovation on power, knowledge, and discourse makes him a main resource for postmodern theories, discourse refers to "an entity of sequences of signs in that they are statements" (Foucault, 2002), abstract matters that enable signs to assign specific repeatable relations to objects, subjects and other statements. A discursive formation is defined as the regularities that produce such discourses.

We are entitled to say things through language, but it also constrains us to express them in certain fixed ways. Even language used in literature, which shoulders the inborn responsibility to press against the limits of such constraints, can never be utterly unique and fully personal insofar since it must respect and conform to the conventions by which language renders indefinite possibilities and conditions for saying things. For postmodernism, language is regarded as a structure or system that precedes us so much that no understandings of us can be sensed outside of language. Human is no longer dominators of language as lord of all, instead, we have retrogressed to be dominated by language. Therefore, the human is "subject to, and subjects of, language's structuring principles and effects (Lucy, 1997)". Just as Han Shaogong puts in the admirable afterword part in A Dictionary of Maqiao, "Humans are linguistic animals, but speaking is actually very difficult for humans" (Lovell, 2005). People in China spare no effort to learn to speak Mandarin, for the purpose of communicating with those who live in every facet of our life, of getting in touch with this rapidly changing world. In the matter of fact, we are standardized by language, by its regulations and restrictions, 
and it turns out that language is ma manipulating humans. Modernism's pursuit of a common language is to be denounced and deconstructed in the postmodern context. Everyone's own, unique dictionary is needed when speaking, and more importance ought to be attached to diversity y rather than universality of language.

He inherits the anti-enlightenment tradition that rejects the equally important relationship among rationality, liberation, and advancement, and argues that modern power and knowledge have integrated into producing a new way of governance. Seemingly unquestionable and naturally existing knowledge, power, institution, and subjectivity, in fact, are accidentally constructed by power and discourse in history (Best and Kellner, 1991). For instance, in one of his magnificent works Madness and Civilization, Foucault tries to illustrate that archaeology is historically constructed as the opposite of nationality and expresses his viewpoints that modern rationality breaks off from madness, and meanwhile attempts to guard against irrational behaviors via exclusive discourse and prohibitive institution. Modern discourse constructs the binary opposition between rationality and madness, between normality and abnormality, so as to consolidate the regulation of rationality and absolute truth. In Dream-Woman, a story about Shuishui who becomes insane after her only son's death, the stereotypical relationship between madness and rationality that is historically constructed by discourse are challenged by a series of odd things happened after her going mad. Shuishui is taken back to her parents' home after getting divorced with Zhihuang, then surprisingly she becomes so famed for her gift in predicting winning numbers of all kinds of lottery that people seek her out from miles and miles away. "Although people normally seen as remote from learning and reason (children, women, the insane, and so on) were mostly regarded as pitiful weaklings, at key, fateful moments they would suddenly become the people who were closest to the truth, who were the most trustworthy and reliable" (Lovell, 2005). It's self-evident that madness and rationality are not naturally opposed to each other but are made so by discourse and stereotypical impressions generated afterward. In certain circumstance, unlike the situation in Dream-woman, they can interchange with and into each other; hence insanity possesses the possibility to topple down truth, which obviously deconstructs the binary opposition of madness and rationality.

Foucault urges to resume discourse, knowledge, and voice that are repressed by the grand narrative. The oppressed voice in history testifies to the invisibility of power. The restatement of oppressed voice is of great significance to human's viewpoint about the definition and location of power. In political discourse, the marginalized try to resist hegemony discourse, which puts personal discourse under constraints of its standard ability, to liberate diversity. In any society, discourse is power, for rules determinant to discourse strengthen the criterion for judging ration, reason, and truth. Those who disobey these rules will put themselves at the risk of being marginalized and ostracized. In Maqiao, Benyi's rumors can never be dismissed for he is the one who has speech rights, referring to "linguistic power, or in other words the right to claim a very definite portion of the sum total of linguistic clout" (Lovell, 2005). Possessors of speech rights cover topics which are followed by the multitude and use words, sentences, and tones which fall into common usage so that their power comes into being in this linguistic expansion process. Those petty people without this right never have the chance to speak or to gain response, the one and only outcome for their words are to be lost in a wasteland of indifference. The former formulates the criterion for truth and rationality, and the latter are marginalized due to their lack of discursive power. Han expresses his disagreement with the linguistic privileges of a fixed number of people, and with their association with power, via the extreme example of Yanzao's loss of speech rights. He also urges the reasonable rights of the people like Yanzao, without whose once oppressed yet heartfelt words, the truth of history will never be complete.

Foucault's project was particularly influenced by Nietzsche, his "genealogy of knowledge" a direct allusion to Nietzsche's "genealogy of morality". In a late interview, he definitively states that he is a Nietzschean. And he adopts Nietzsche's viewpoint that knowledge by virtue is perspectival, hence multiple perspectives are needed to interpret history and facts. In Maqiao Bow, the Annals of the Ministry for the Suppression of Rebellion edited by the Qing authorities and the New County Annals are cited to narrate the historical story of Ma Sanbao. Totally opposite images of the same person are recorded in these two documentary historical records; one is among those who are included in the role of "Peasant Rebellion Leaders", and as one madman into whose hands over seven hundred villagers in Maqiao waste their own lives (Lovell, 2005). With regard to the most significant event in Maqiao, the disorder wrought by the Lotus Bandits, two versions of history are presented to the author as well as to the readers; therefore, the question of what on earth is the truth of history is to be brought out. Historical facts are manifold, multi-perspectives based on different standpoint and social class may lead to dissimilar historical records. Hence, in postmodernists' eyes, the truth of history is nothing but multiple and structureless assemblages rather than as authoritative grounds for an understanding of human being and culture.

Guo, J. (2018). On the postmodernity in a dictionary of Maqiao. International Journal of Linguistics, Literature and Culture, 4(4), 17-24. https://doi.org/10.21744/ijllc.v4n4.256 


\subsection{Postmodernity from the Narrative Perspective}

The word "modern" embodies temporal meaning. The concept "modernity" can only be conceived in the framework of linear and irreversible historical time, so continuity is the basis for establishing the comprehensible meaning of "modernity". Postmodernism stems from modernism, while rebels against modernism, thus the most obvious feature of postmodern literary works is their narrative discontinuity. They apply fragmented narratives to deconstruct the logic of cause and effect, and further to fail the modern attempt to reveal the nature of the development and changes of things. A Dictionary of Maqiao collects 115 entries on the local dialect, including those of time, place, people, object, name, animal, plant, and a variety of adjectives. Basically, there is no logical relationship between each entry, no core plot and narrative clue in the whole work, thus the fragmented narrative completely breaks the traditional narrative focus and continuity.

Jean Francois Lyotard, a French philosopher, and postmodernist, is credited with his articulation of postmodernism after the late 1970s, and his contribution of making postmodernism a household term by his The Postmodern Condition: A Report on Knowledge. His research is labeled by a fierce opposition to meta-narrative, and he proposes an extremely simplified definition of postmodernism as incredulity towards meat-narrative. Lyotard argues that we have ceased to believe that narratives of this kind are adequate to represent and contain us all. We have become alert to difference, diversity, the incompatibility of our aspirations, beliefs, and desires, and for that reason, postmodernity is characterized by an abundance of micro-narratives (1984). In the context of postmodernism, he further pinpoints, the single standard to determine all the differences and unify all the meta-narrative discourse in human's history has been invalidated, so does the grand-narrative of pursuing absolute freedom and truth. Consequently, the knowability of everything by science is no longer immutable and absolute truth thus becomes one of the various discourses. People in Maqiao deem science as laziness, productions of technology as being thought up by lazybones. In the folk discourse, scientific ability to assist human and to improve social development disappears, merely with sniffy association with Maming who lives in House of Immortals. For instance, Maming walks into a Z-shape in order to spend less strength and carry a load of water back home. Passersby make fun of him, asking him to put down water and sing them a song. They have no idea of the scientific truth that walking in Z-shape can preserve people's strength. In terms of villagers here, science is the no longer absolute truth, just one kind of discourse in daily life. Thus it can be seen that this novel succeeds in revealing the long-standing opposition between modern science and local traditions or that between the east and the west (Leebhouts \& Zhang, 2017).

Lyotard deems Freud as a theorist who conducts research about the destructive yet transformative effects of human's desire. Sigmund Freud, all of us who might regard ourselves as fully socialized have been successfully Oedipalized. This occurs when our pre-Oedipal selves, utterly abandoned to the pleasure principle, convert to the sway of the reality principle knowing that the fulfillment of our pleasures must be delayed in order to attend to the immediate demands of reality. We actually don't give up our desire to fulfill our every desire, instead, we agree to the postponement of our pleasures for the sake of doing reality's urgent bidding, which is actually in our best interests. Hence, we go to work to be able to play, or we refrain from killing someone who annoys us because we know that in succumbing to that pleasure the consequences may be such as to put at risk the full expression of our future pleasures. Lyotard holds that two conflicting desire driving humans, namely eros (the life drive) and thanatos (the death drive), are intertwined in Freudian theory of the unconscious, and both presented in human's desire (Best and Kellner, 1991). In what Freud calls primary process, in which the impulsive, child-like portion of the psyche operates on the "pleasure principle" and only takes into account what it wants and disregards all consequences, human's desire is manifested directly through images. In a secondary process that operates on the "reality principle", discourse is revealed in accordance with the rules and rationality of ego. Since desire, expressed in discourse, is constrained by rules and restrictions of language, discourse seems more abstract and rational than desire and image through which desire is revealed, and follows the stereotype routine. This complex process from image to discourse is reflected in the entry of Sweet. At first arrival, Han never quite gets used to Maqiao people's expression of flavors; the word of sweet epitomizes anything that tastes good. But after he experiences starvation himself, he comprehends the reason of the sweet expression. In the darkness he goes back to the village, having finished all the farm work, covered in mud from head to toe. Without washing hands and slapping mosquitoes, he finishes eating five bowls of rice in one breath and still doesn't know what it tastes. In the libido process, fiercely urged by the desire of starvation Han only can satisfy his desire in the image of food without language. While having moved on to the next process after desire being fulfilled, Han can apply language to express his hungry feeling and the taste of food in accordance with linguistic regulations. Therefore, discourse seems more abstract than desire and image, and the word sweet deserves the possibility to generalize all good flavors. 


\subsection{Postmodernity from the Feminist Perspective}

Emerged in the 1960s, feminism tries every means to expose and fight against patriarchal oppression, to pursue political, economic, and social rights and equal opportunities for women with the other sex. From the 1980s onwards, diversity in sex, race, class and subjective position begins to arouse feminists' attention. Consequently, postmodern feminism comes into foe and feminists starts to attach more importance to the particularity of their position and the discrepancy with a male. In Maqiao and countries nearby, there are no female nomenclatures, most names function only by adding the word "little" to the male name. Women are always related to people who are in a lower position in society. Having knowledge of the female namelessness, people hardly comprehend their social status and living conditions here. According to Han Shaogong's interpretation, "[in] Maqiao, female namelessness is, in fact, male namedness" (Lovell, 2005). Female suffer a lot from the male domination and oppression to the extent that they even fail to possess a name, let alone political, economic and social equalities.

Feminist, perceiving some dubious flaws in modern theory and politics, are inclined to criticize modernism and essentialism for its endorsement and shield for the oppression of women (Best and Kellner, 1991). Especially "Man" generalizing all human in humanism discourse, directly covers up the difference between male and female, and gives secret support to male domination of female. Man is the quintessence of human, while the woman is just an accessory sex. The binary opposition between two sexes, which dates back to the years when Plato and Aristotle lived, makes an excuse for male domination, and leaves all household duties to female, excluding them from public life and from making their own sound. In Speech Right, women in Maqiao don't have speech rights as men do. When men are speaking, they just sit aside silently, breastfeeding child or sewing clothes. Moreover, they never receive an invitation to attend the big Village Meetings of the People. Feminism and postmodernism are supplementary to each other. The former contributes to postmodernism criticizing the generalization of all human by "Man" in humanism discourse, and the latter lays stress on plurality, diversity, alterity, and inhomogeneity, thus appeals to feminists and furnishes feminist movement with brand new Philosophical Basis. Han Shaogong, on behalf of postmodern feminist, fiercely rebuts the humanism discourse in English language, revealed by the substitution of the word "man" with all human, by the obviously masculinized words of "chairman" and "minister".

Postmodern feminism pays more attention to the distinction between man and woman, by virtue of race, class, so on and so forth, no longer as modern feminists especially those who participate in the first wave feminist movement, they blindly urge female equality in every facet with male ignoring their inborn difference. Han expresses his doubts about whether this language misrepresentation produces an effect on Maqiao women's sexual biology and sexual psychology. However, to all appearances, they all form into men's habits and lead their own lives in accordance with men's ethics. Even for the greatest distinctive biological feature of menstruation, they seem so ashamed and refer to it as "that thing". Women in Maqiao are despised and their female gender is ignored. They wrap cloth straps tightly around their chest and dress in men's clothes, they have a loud and bulky voice, they curse even get into a fight a lot. They may ask for leave from the paddy fieldwork because of a village fair, but they never take a rest when they are on their periods. To a larger extent, differences between the two genders are wiped out and male becomes the only gender in Maqiao, thus women would never get their due respect in this miniature version of the whole patriarchal society. Ironically Han shows his critical attitude towards female's namelessness and their pretense to duplicate behaviors even psychology of the opposite sex. Only if obtaining acknowledge of their instinct difference can equality is possible to be achieved.

\section{Conclusion}

Han Shaogong's A Dictionary of Maqiao coheres to certain postmodern theories. In the context of postmodernism, Han applies discursive theory of Michel Foucault and narrative theory of Jean Francois Lyotard to demonstrate his viewpoints that discourse generates the binary opposition such as one between madness and rationality, in the same way, it constructs history through its indivisible association with power, therefore the genuine truth of history is to be revealed by the deconstruction of discourse and power. The novel also destructs the traditional narrative focus and continuity through its fragmented narrative of 115 entries on local dialect without core plot and any chronological sequence. Moreover, postmodern feminism is also embodied in the novel, in which more attention is attached to the diversity rather than equality between male and female.

Guo, J. (2018). On the postmodernity in a dictionary of Maqiao. International Journal

of Linguistics, Literature and Culture, 4(4), 17-24.

https://doi.org/10.21744/ijllc.v4n4.256 
Conflict of interest statement and funding sources

The author declared that she has no competing interest. The study was financed by the author herself.

Statement of authorship

The author has a responsibility for the conception and design of the study. The author has approved the final article.

Acknowledgments

The author would like to thank the editor of journal especially Ted F.L. Jing, Ph.D. for their valuable time and advice. 


\section{References}

Best, S., \& Kellner, D. (1991). Postmodern theory: Critical interrogations. Guilford Press.

Foucault, M. (2013). Archaeology of knowledge. Routledge.

Han Shaogong. (2006). A Dictionary of Maqiao. Shenyang: Chun Feng Art Publishing House.

Leebhouts, Mark \& Xuerui, Zhang. (2017). On the Bantering Nature in Han Shaogong's Maqiao Dictionary. Contemporary Writers Review, (04), 16-24.

Lovell, J. (2003). 'A dictionary of Maqiao'by Han Shaogong.

Lucy, N. (1997). Postmodern literary theory: An introduction (p. 172). Oxford: Blackwell.

Lyotard, J. F. (1984). The postmodern condition: A report on knowledge (Vol. 10). U of Minnesota Press. 


\section{Biography of Author}

\begin{tabular}{|l|l|}
\hline \hline Jing Guo received her MA from Guangdong University of Foreign Studies in 2013, and \\
now is a teaching assistant of the School of Foreign Languages, Shanxi Normal \\
University. Her research interests include ELT and English and American literature.
\end{tabular}

